a temperature of $480^{\circ} \mathrm{C}$. The low-temperature product obtained was activated by treatment with superheated steam at a temperature of $950^{\circ} \mathrm{C}$. This second stage of the treatment was carried out in the same type of retort. The yield of active carbon was 20-25 per cent of the coal originally carbonised. Some of the active carbon sized to a grade from $\frac{1}{4}-\frac{1}{8}$ in. is being used at the Station for the recovery of spirit'and benzole from coal gas.

The low-temperature carbonisation of coal produces large amounts of tar for which new industrial outlets are continually being sought. Similarly, the whole of the high-temperature tar produced in Great Britain does not always find a ready market. Processes such as hydrogenation-cracking which employ tars and tar distillates as raw materials for the production of fuel oils are therefore worthy of examination.

Experimental work has been in progress to determine the conditions and plant necessary for the conversion of tars and tar oils into materials, such as motor spirit, for which the market is relatively large. The process is one of hydrogenation-cracking and is operated under high pressures of hydrogen (normally about 200 atmospheres) and at elevated temperatures $\left(350^{\circ}-550^{\circ}\right.$ C.). The most satisfactory conditions and catalysts are being determined by experiment, and continuously operated plants are in use in which the variables of the process are being studied. The catalyst favoured at present for the treatment of crude low-temperature tars is a sulphide of molybdenum supported on a porous gel, but for selected oil distillates more active catalysts are available.

It has been found that low-temperature tar with no pre-treatment, other than filtration to remove dust, can be hydrogenated satisfactorily. In one passage through the supported molybdenum catalyst there is obtained a product which is free from pitch and which contains motor spirit amounting to 45 per cent of the tar treated. By re-processing the high-boiling oils the total yield of spirit becomes 76 per cent by weight of the tar and 100 per cent by volume. Tar fractions can be treated with greater ease than crude tar. Creosote, for example, is much more readily treated than high-temperature tar. The crude spirit requires very little refining to make it a stable water-clear motor spirit having satisfactory properties. It has a good anti-knock value (octane number 70-75).

The scale of operation of the process has been increased in stages, the latest development being the design and construction of a plant capable of dealing with 1-2 tons of raw material per day. In erecting this plant, two main tasks were undertaken. The first of these consisted in working out a technique or method of operation which should be applicable to a large-scale plant; the second entailed the examination of the effect of variables (temperature, pressure, through-put, etc.) with the view of determining the best working conditions for the treatment of various raw materials. The first task has been accomplished, and work on the second is in progress.

The Fuel Research Station is also the headquarters of the Physical and Chemical Survey of the National Coal Resources, which is examining the coal seams of Great Britain. Much interest was taken in samples which were exhibited to show the great diversity in the appearance and properties of different types of coal, and in the methods and apparatus used in their examination.

\title{
The Kiss Precise
}

GOR pairs of lips to kiss maybe

Involves no trigonometry.

'Tis not so when four circles kiss

Each one the other three.

To bring this off the four must be

As three in one or one in three.

If one in three, beyond a doubt

Each gets three kisses from without.

If three in one, then is that one

Thrice kissed internally.

Four circles to the kissing come.

The smaller are the benter.

The bend is just the inverse of

The distance from the centre.

Though their intrigue left Euclid dumb

There's now no need for rule of thumb.
Since zero bend's a dead straight line And concave bends have minus sign, The sum of the squares of all four bends Is half the square of their sum.

To spy out spherical affairs

An oscular surveyor

Might find the task laborious, The sphere is much the gayer, And now besides the pair of pairs A fifth sphere in the kissing shares. Yet, signs and zero as before, For each to kiss the other four The square of the sum of all five bends Is thrice the sum of their squares.

F. SODDY. 